\title{
Phthalates, Adipates, Citrate and Some of the Other Plasticizers Detected in Japanese Retail Foods: a Survey
}

\author{
Yukari Tsumura, Susumu Ishimitsu, Akiko Kaihara, Kimihiko Yoshii, and Yasuhide Tonogai* \\ National Institute of Health Sciences, Osaka Branch, 1-1-43 Hoenzaka, Chuo-ku, Osaka 540-0006, Japan
}

(Received May 27, 2002; Accepted September 9, 2002)

\begin{abstract}
Plasticizers in Japanese retail foods were determined by gas chromatography/mass spectrometry (GC/MS) (SIM). The plasticizers tested were as follows: dibutyl phthalate, butylbenzyl phthalate, di(2-ethylhexyl) phthalate (DEHP), diisononyl phthalate, di(2-ethylhexyl) adipate, diisononyl adipate (DINA), dialkyl adipate, dibutyl sebacate, $O$ acetyl tributyl citrate (ATBC) and diacetyllauroyl glycerol (DALG). A total of 93 samples were analyzed. For the analysis, each sample was extracted by a method suitable to its nature and cleaned using Florisil ${ }^{\circledR}$ and Bondesil PSA ${ }^{\circledast}$ dual layer columns. The recovery of plasticizers from fortified food samples was 62.0-131.0\%, except in the case of DINA. The limit of detection (LOD) was different for each sample species and plasticizers. For example, the LOD for plasticizers in retort-pouched baby food was $0.0004-0.037 \mu \mathrm{g} / \mathrm{g}$. A retort-pouched baby food sample was found to be contaminated by DEHP at the Japanese tolerable daily intake (TDI) level, $40 \mu \mathrm{g} / \mathrm{kg} / \mathrm{day}$. The source of contamination was presumed to be disposable gloves because the baby food was produced before the prohibition of DEHPcontaining poly vinyl chloride (PVC) gloves by the Japanese government. After that prohibition, products generally contained much lower levels of DEHP. A higher level of DALG was detected in the other baby food samples, although it became clear that DALG did not originate as contamination from plastics but was added as a food additive. ATBC was detected in bottled sake samples at levels of around 3-7 $\mu \mathrm{g} / \mathrm{g}$, having migrated from the gasket of the bottle cap. ATBC and DALG levels in the above foods were quite low compared with their no observed adverse effect level (NOAEL) or guideline levels as food additives.
\end{abstract}

Key words — plasticizer, food, survey, phthalate, adipate

\section{INTRODUCTION}

A wide range of plastic materials are used as containers or wrappings in such a way that they contact foods directly. It is known in the field of food safety that additives or monomers in plastics may migrate into foods. Poly vinyl chloride (PVC) and poly vinylyden chloride (PVDC) contain plasticizers in larger amounts than other additives, such as anti-oxidants or stabilizers; therefore their degree of migration would be larger. ${ }^{1)}$

The authors conducted a study to determine the Japanese daily intake of phthalates, a common and important group of plasticizers, by means of a duplicate diet study based on meals obtained from hospitals and packed lunches from convenience stores in 1999. All of the packed lunches and parts of meals

\footnotetext{
*To whom correspondence should be addressed: National Institute of Health Sciences, Osaka Branch, 1-1-43 Hoenzaka, Chuoku, Osaka 540-0006, Japan. Tel.: +81-6-6941-1533; Fax: +816-6942-0716; E-mail: tonogai@nihs.go.jp
}

from hospitals were found to contain high levels of di(2-ethylhexyl) phthalate (DEHP). ${ }^{2,3)}$ The authors ascertained the source of the contamination to be disposable PVC gloves used in cooking. ${ }^{3)}$ DEHP causes liver or testicular damage in rats and mice, and the "no observed adverse effect level" (NOAEL) has been shown to be 3.7 or $14 \mathrm{mg} / \mathrm{kg} / \mathrm{day}^{4}{ }^{4,5)} \mathrm{In}$ June 2000 , the Japanese government set the tolerable daily intake (TDI) level for DEHP to be $40-140 \mu \mathrm{g} / \mathrm{kg} /$ day, and prohibited the use of DEHP-containing gloves for food contact purposes. ${ }^{6}{ }^{6}$ The authors investigated the DEHP levels in retail packed lunches after the prohibition of PVC gloves and found them to be about $4 \%$ of the levels before prohibition. ${ }^{7}$

In a previous study, a high DEHP content of $6 \mu \mathrm{g} /$ $\mathrm{g}$ was also found in retort-pouched baby food, with the source being PVC tubing used in production. ${ }^{2)}$ No survey of plasticizers in Japanese foods had been done adequately at that time, so that unexpected high DEHP contamination was successively encountered. Widespread use of PVC for gloves, tubing or some 
Table 1. List of Plasticizers Tested

\begin{tabular}{|c|c|c|c|c|c|c|c|}
\hline No. & Compound & Abbreviation & CAS No. & $\begin{array}{c}\text { Ions for } \\
\text { quantification } \\
(\mathrm{m} / \mathrm{e})\end{array}$ & $\begin{array}{c}\text { Ions for } \\
\text { confirmation } \\
(\mathrm{m} / \mathrm{e})\end{array}$ & $\begin{array}{l}\text { Internal } \\
\text { standard }\end{array}$ & $\begin{array}{c}\text { Relative } \\
\text { retention } \\
\left.\text { time }(\mathrm{RRT})^{a}\right)\end{array}$ \\
\hline 1 & Di- $n$-butyl phthalate & DBP & $84-74-2$ & 149 & 104,150 & DBP- $\left.d_{4}{ }^{b}\right)$ & 0.832 \\
\hline 2 & $n$-Butylbenzyl phthalate & BBP & $85-68-7$ & 149 & 206 & $\mathrm{BBP}-d_{4}{ }^{b)}$ & 1.000 \\
\hline 3 & Di(2-ethylhexyl) phthalate & DEHP & $117-81-7$ & 149 & 167,279 & DEHP- $\left.d_{4}{ }^{b}\right)$ & 1.078 \\
\hline 4 & Diisononyl phthalate & DINP & $28553-12-0$ & 149 & 293 & $\mathrm{DNP}-d_{4}{ }^{b)}$ & $1.259^{d)}$ \\
\hline 5 & Di- $n$-alkyl adipate $(C=6,8,10)$ & DAA & & 129 & 213 & f) & $0.917^{d)}$ \\
\hline 6 & Di(2-ethylhexyl) adipate & DEHA & $103-23-1$ & 129 & 147 & DEHA- $\left.d_{8} c\right)$ & 1.013 \\
\hline 7 & Diisononyl adipate & DINA & $33703-08-1$ & 129 & 255 & f) & $1.140^{d)}$ \\
\hline 8 & Dibutyl sebacate & DBS & $109-43-3$ & 185 & 241 & f) & 0.924 \\
\hline 9 & $O$-Acetyl tributyl citrate & ATBC & $77-90-7$ & 185 & 129 & f) & 0.956 \\
\hline 10 & Diacetyllauroyl glycerol $^{e}$ ) & DALG & $30899-62-8$ & 159 & 183 & f) & $0.966^{d)}$ \\
\hline
\end{tabular}

a) Relative retention time compared to BBP. Retention time of BBP was $22.92 \mathrm{~min} . b$ ) Quantification ion was 153 for deuterated isomer. c) Quantification ion was 137 for deuterated isomer. $d$ ) RRT of the highest peak is shown because the standard material was a mixture of isomers. $e$ ) Produced by acetylation of monolauroyl glycerol from vegetable oil. $f$ ) Internal standard was not used.

of the other purposes can distort the estimation of daily intake. The estimated daily intake data on duplicated diet samples in 1999 has lost its reliability because the intake of DEHP should have been lowered by the prohibition of PVC gloves.

The purpose of this study is to ascertain the presence or absence of food contamination due to plasticizers by conducting a wide survey. This study is a necessary step in the accurate estimation of intake. Ten plasticizers were analyzed and are abbreviated in Table 1. These include 4 phthalates [di- $n$ butylphthalate (DBP), $n$-butylbenzyl phthalate (BBP), DEHP and diisononyl phthalate (DINP)], 3 adipates [di- $n$-alkyl adipate (DAA), di(2ethylhexyl) adipate (DEHA), diisononyl adipate (DINA)] and 3 other plasticizers [dibutyl sebacate (DBS), $O$-acetyl tributyl citrate (ATBC) and diacetyllauroyl glycerol (DALG)]. These plasticizers were either frequently detected in foods in our previous study ${ }^{2,3)}$ or were often added to the wraps or containers for food consumed in Japan. ${ }^{1)}$ The isotope dilution technique was partly used for quantification, and the surrogates are also specified in Table 1.

\section{MATERIALS AND METHODS}

Food Samples — Retail food samples were purchased from stores in the Kinki area of Japan from September 2000 to February 2001. The manufacturers of these foods were distributed throughout Japan. Number of samples/type of samples are men- tioned in Table 2. Three baby food samples in which high DEHP or DALG was detected, were purchased and tested repeatedly.

Chemicals — Plasticizers and the deuterated isomers were purchased from Wako Pure Chemicals (Osaka, Japan), Hayashi Pure Chemicals (Osaka, Japan), Tokyo Kasei Kogyo (Tokyo, Japan) and Kanto Kagaku (Tokyo, Japan). Each compound was dissolved in $n$-hexane (stock solution) and diluted by $n$-hexane for calibration curves or acetonitrile for recovery tests (working solutions). A Florisil + Bondesil PSA column was prepared by packing $2 \mathrm{~g}$ Florisil PR ${ }^{\circledR}(60-100$ mesh, Floridin Co., New York, U.S.A.) as a slurry in a glass syringe $(1.5 \mathrm{~cm}$ i.d. $\times 11 \mathrm{~cm})$ with a cotton plug, and $0.5 \mathrm{~g}$ Bondesil PSA $^{\circledR}$ (acid-washed silica bonded by ethylenediamine- $N$-propyl, $40 \mu \mathrm{m}$, Varian Inc., CA, U.S.A.) and $1 \mathrm{~g}$ anhydrous sodium sulfate $\left(\mathrm{Na}_{2} \mathrm{SO}_{4}\right)$ were placed on this slurry using $n$-hexane. The system was then passed through $10 \mathrm{ml}$ acetone and $10 \mathrm{ml}$ $n$-hexane before use. Extrelut $20^{\circledR}$ was purchased from Merck (Darmstadt, Germany). Acetone, $n$-hexane, water and $\mathrm{Na}_{2} \mathrm{SO}_{4}$ were of a special grade for phthalates purchased from Kanto Kagaku and Wako Pure Chemicals. Acetonitrile and $\mathrm{NaCl}$ were of pesticide analysis grade (Wako Pure Chemicals). Florisil and $\mathrm{NaCl}$ were heated at $200^{\circ} \mathrm{C}$ for $2 \mathrm{hr}$ and cooled before use.

Apparatus — The homogenizer used was a Dancing Agitator, Hirosawa Ironworks (Tokyo, Japan). To mix a homogenized sample with acetonitrile, Ultra-Turrax, Janke \& Kunkel GmbH \& Co (Staufen, Germany) was used. The rotary evaporator was an 
Table 2. Plasticizers in Food Samples; Minimum, Maximum and Median Levels Detected ${ }^{a}$ )

\begin{tabular}{|c|c|c|c|c|c|c|c|}
\hline \multirow[t]{2}{*}{ Food species } & \multirow{2}{*}{$\begin{array}{l}\text { Number } \\
\text { of } \\
\text { samples }\end{array}$} & \multicolumn{6}{|c|}{$\begin{array}{c}\text { Concentrations }(\mu \mathrm{g} / \mathrm{g}) \\
\text { minimum - maximum (median) }\end{array}$} \\
\hline & & DBP & $\mathrm{BBP}$ & DEHP & DINP & DEHA & ATBC \\
\hline \multicolumn{8}{|l|}{ Beverages } \\
\hline Sake & 5 & $\begin{array}{l}\mathrm{ND}^{b)}-0.006 \\
(\operatorname{tr})\end{array}$ & ND & $\begin{array}{l}\text { ND-0.014 } \\
\text { (ND) }\end{array}$ & ND & $\begin{array}{l}\left.\mathrm{ND}-\mathrm{Tr}^{c}\right) \\
(\mathrm{ND})\end{array}$ & $\begin{array}{l}\text { ND-7.30 } \\
(3.14)\end{array}$ \\
\hline Wine & 3 & $\begin{array}{l}\operatorname{Tr}-0.66 \\
(0.007)\end{array}$ & $\begin{array}{l}\text { ND-0.002 } \\
(0.001)\end{array}$ & ND & ND & ND & $\begin{array}{l}\text { ND-0.009 } \\
\text { (ND) }\end{array}$ \\
\hline Beer & 3 & $\begin{array}{l}\text { ND-Tr } \\
(\mathrm{ND})\end{array}$ & $\begin{array}{l}\text { ND-Tr } \\
\text { (ND) }\end{array}$ & $\begin{array}{l}\text { ND-0.027 } \\
\text { (ND) }\end{array}$ & ND & $\begin{array}{l}\mathrm{ND}-\mathrm{Tr} \\
(\mathrm{ND})\end{array}$ & ND \\
\hline \multicolumn{8}{|l|}{ Fat and oil } \\
\hline Butter & 3 & ND & $\begin{array}{l}\text { ND-0.056 } \\
\text { (ND) }\end{array}$ & $\begin{array}{l}1.02-2.83 \\
(1.61)\end{array}$ & ND & $\begin{array}{l}0.79-2.78 \\
(1.40)\end{array}$ & $\begin{array}{l}\mathrm{Tr}-0.56 \\
(0.064)\end{array}$ \\
\hline Margarine & 3 & ND & ND & ND & ND & ND & ND \\
\hline Fat spread & 3 & ND & $\begin{array}{l}\text { ND-0.13 } \\
(\mathrm{ND})\end{array}$ & ND & ND & ND & ND \\
\hline vegetable oil & 8 & $\begin{array}{l}\text { ND-2.40 } \\
(\mathrm{ND})\end{array}$ & $\begin{array}{l}\text { ND-0.62 } \\
(0.037)\end{array}$ & $\begin{array}{l}\text { ND-1.75 } \\
(0.45)\end{array}$ & ND & $\begin{array}{l}\text { ND-0.49 } \\
(0.040)\end{array}$ & ND \\
\hline \multicolumn{8}{|l|}{ Dairy products } \\
\hline Cheese & 3 & ND & $\begin{array}{l}\operatorname{Tr}-0.008 \\
(\mathrm{Tr})\end{array}$ & $\begin{array}{l}0.33-0.57 \\
(0.35)\end{array}$ & ND & $\begin{array}{l}0.036-0.046 \\
(0.044)\end{array}$ & $\begin{array}{l}0.052-0.22 \\
(0.080)\end{array}$ \\
\hline Milk & 3 & ND & ND & $\begin{array}{l}0.063-0.10 \\
(0.064)\end{array}$ & ND & $\begin{array}{l}0.040-0.081 \\
(0.049)\end{array}$ & $\begin{array}{l}0.013-0.11 \\
(0.013)\end{array}$ \\
\hline Ice cream & 3 & ND & ND & $\begin{array}{l}0.17-0.39 \\
(0.17)\end{array}$ & ND & $\begin{array}{l}0.097-0.15 \\
(0.097)\end{array}$ & $\begin{array}{l}0.016-0.026 \\
(0.024)\end{array}$ \\
\hline \multicolumn{8}{|l|}{ Refreshments } \\
\hline Cookies & 3 & $\begin{array}{l}\text { ND-0.070 } \\
(0.027)\end{array}$ & ND & $0.10-0.68$ & ND & $\begin{array}{l}\text { ND-0.12 } \\
(0.010)\end{array}$ & $\begin{array}{l}\text { ND-0.028 } \\
\text { (ND) }\end{array}$ \\
\hline Chocolate & 3 & $\begin{array}{l}\text { ND-0.027 } \\
\text { (ND) }\end{array}$ & $\begin{array}{l}\mathrm{ND}-\mathrm{Tr} \\
(\mathrm{ND})\end{array}$ & $\begin{array}{l}0.077-0.21 \\
(0.080)\end{array}$ & ND & $\begin{array}{l}0.009-0.023 \\
(0.015)\end{array}$ & ND \\
\hline Solty pastry & 3 & $\mathrm{ND}$ & $\begin{array}{l}\text { ND-Tr } \\
\text { (ND) }\end{array}$ & $\begin{array}{l}\mathrm{Tr}-0.15 \\
(0.071)\end{array}$ & ND & $\begin{array}{l}\text { ND-0.012 } \\
\text { (ND) }\end{array}$ & $\begin{array}{l}\mathrm{ND}-\mathrm{Tr} \\
(\mathrm{ND})\end{array}$ \\
\hline \multicolumn{8}{|l|}{ Fast foods } \\
\hline Hamburger set & 3 & ND & $\begin{array}{l}\text { ND-Tr } \\
(\mathrm{ND})\end{array}$ & $\begin{array}{l}\text { ND-0.039 } \\
\text { (ND) }\end{array}$ & ND & ND & ND \\
\hline Gyu-don & 3 & ND & ND & ND & ND & ND & ND \\
\hline Pizza & 3 & ND & $\begin{array}{l}\text { ND-0.002 } \\
(\mathrm{Tr})\end{array}$ & $\begin{array}{l}0.096-0.40 \\
(0.23)\end{array}$ & ND & $\begin{array}{l}\text { ND-0.015 } \\
\text { (ND) }\end{array}$ & ND \\
\hline \multicolumn{8}{|l|}{ Instant food } \\
\hline retort-pouched food & 11 & ND & $\begin{array}{l}\text { ND- } 0.010 \\
(\mathrm{Tr})\end{array}$ & $\begin{array}{l}\text { ND-0.44 } \\
(0.067)\end{array}$ & ND & $\begin{array}{l}\text { ND-0.015 } \\
\text { (ND) }\end{array}$ & $\begin{array}{l}\text { ND-0.003 } \\
\text { (ND) }\end{array}$ \\
\hline dry noodles & 3 & $\begin{array}{l}\text { ND-0.051 } \\
(\mathrm{Tr})\end{array}$ & ND & $\begin{array}{l}\text { ND-0.42 } \\
(0.092)\end{array}$ & ND & $\begin{array}{l}\text { ND-0.017 } \\
\text { (ND) }\end{array}$ & $\begin{array}{l}\text { ND-Tr } \\
\text { (ND) }\end{array}$ \\
\hline \multicolumn{8}{|l|}{ Baby food } \\
\hline retort-pouched baby food & 13 & $\begin{array}{l}\text { ND-0.011 } \\
\text { (ND) }\end{array}$ & $\begin{array}{l}\text { ND-0.003 } \\
(\mathrm{Tr})\end{array}$ & $\begin{array}{l}\text { ND-4.25 } \\
(0.081)\end{array}$ & $\begin{array}{l}\text { ND-0.064 } \\
\text { (ND) }\end{array}$ & $\begin{array}{l}\text { ND-0.44 } \\
(0.006)\end{array}$ & $\begin{array}{l}\text { ND-0.016 } \\
\text { (ND) }\end{array}$ \\
\hline baby snack & 5 & $\begin{array}{l}\text { ND-Tr } \\
\text { (ND) }\end{array}$ & $\begin{array}{l}\text { ND-Tr } \\
\text { (ND) }\end{array}$ & $\begin{array}{l}0.12-0.45 \\
(0.32)\end{array}$ & $\begin{array}{l}\text { ND-1.83 } \\
(0.17)\end{array}$ & $\begin{array}{l}\text { ND-0.018 } \\
(0.010)\end{array}$ & $\begin{array}{l}\text { ND-0.012 } \\
\text { (ND) }\end{array}$ \\
\hline Infant formula & 6 & $\begin{array}{l}0.013-0.25 \\
(0.14)\end{array}$ & $\begin{array}{l}\text { ND-0.003 } \\
\text { (ND) }\end{array}$ & $\begin{array}{l}0.028-0.28 \\
(0.13)\end{array}$ & ND & $\begin{array}{l}\mathrm{Tr}-0.041 \\
(0.010)\end{array}$ & ND \\
\hline Total & 93 & ND-2.40 & ND-0.62 & ND-4.25 & ND-1.83 & ND-2.78 & ND-3.14 \\
\hline
\end{tabular}

a) DINA, DBS and DAA were not detected in any sample. DALG was detected only in two samples of retort-pouched baby food at levels of 5.47 and $4.76 \mu \mathrm{g} / \mathrm{g}$. $b$ ) ND: not detected; ND < LOD. $c$ ) Tr: trace level; LOD $\leq \operatorname{Tr}<$ LOQ. 
Table 3. Limit of Detection (LOD) for Plasticizers in Food Samples ${ }^{a}$ )

\begin{tabular}{|c|c|c|c|c|c|c|c|c|c|c|c|c|c|}
\hline \multirow{2}{*}{ Food species } & \multirow{2}{*}{$\begin{array}{l}\text { Method of } \\
\text { analysis }^{b)}\end{array}$} & \multirow{2}{*}{$\begin{array}{l}\text { Sampling } \\
\text { weight (g) }\end{array}$} & \multirow{2}{*}{$\begin{array}{c}\text { Number of } \\
\text { blank test }\end{array}$} & \multicolumn{10}{|c|}{ Limit of detection $(\mu \mathrm{g} / \mathrm{g})^{c)}$} \\
\hline & & & & DBP & BBP & DEHP & DINP & DAA & DEHA & DINA & DBS & ATBC & DALG \\
\hline Retort-pouched baby food & A & 50 & 6 & 0.003 & 0.0004 & 0.037 & 0.006 & 0.003 & 0.0009 & 0.008 & 0.002 & 0.0006 & 0.003 \\
\hline Hamburger, retort-pouched food & A & 50 & 9 & 0.099 & 0.0004 & 0.019 & 0.006 & 0.003 & 0.004 & 0.014 & 0.002 & 0.0006 & 0.003 \\
\hline Gyu-don, ${ }^{d)}$ pizza & A & 25 & 9 & 0.20 & 0.0008 & 0.037 & 0.01 & 0.006 & 0.007 & 0.027 & 0.003 & 0.001 & 0.006 \\
\hline Sake, wine & B & 100 & 5 & 0.001 & 0.0002 & 0.004 & 0.003 & 0.002 & 0.0003 & 0.004 & 0.0008 & 0.0004 & 0.002 \\
\hline Beer & $\mathrm{C}$ & 20 & 3 & 0.066 & 0.001 & 0.004 & 0.02 & 0.008 & 0.0005 & 0.02 & 0.004 & 0.002 & 0.008 \\
\hline Butter, margarine, fat spread & $\mathrm{D}$ & 2 & 4 & 0.28 & 0.01 & 0.19 & 0.2 & 0.08 & 0.021 & 0.2 & 0.04 & 0.02 & 0.08 \\
\hline Vegetable oil & E & 2 & 4 & 0.051 & 0.01 & 0.053 & 0.2 & 0.08 & 0.017 & 0.2 & 0.04 & 0.02 & 0.08 \\
\hline Refreshments, cheese, dry noodles & $\mathrm{F}$ & 5 & 8 & 0.015 & 0.004 & 0.029 & 0.06 & 0.03 & 0.005 & 0.08 & 0.02 & 0.006 & 0.03 \\
\hline Infant formula & $\mathrm{F}$ & 20 & 3 & 0.002 & 0.001 & 0.013 & 0.02 & 0.008 & 0.001 & 0.02 & 0.004 & 0.002 & 0.008 \\
\hline Milk & G & 10 & 4 & 0.010 & 0.002 & 0.025 & 0.03 & 0.02 & 0.010 & 0.04 & 0.008 & 0.003 & 0.02 \\
\hline Ice cream & G & 5 & 4 & 0.020 & 0.004 & 0.049 & 0.06 & 0.03 & 0.020 & 0.08 & 0.02 & 0.006 & 0.03 \\
\hline
\end{tabular}

a) Limit of quantification (LOQ) was set at a level twice that of LOD. $b$ ) The details of each method are described in the text. $c$ ) Limit of detection is calculated as three times the standard deviation of the plasticizer levels detected in the blank test, or as the mechanical detection limit of GC/MS. $d$ ) Boiled rice with spiced beef and onion.

RE 111 Rotavapor (Buchi, Shibata Kagaku Kikai Kogyo, Tokyo, Japan) equipped with a water bath and vacuum pump (Model JS-75A, Advantec, Tokyo, Japan). The water bath was maintained at $40^{\circ} \mathrm{C}$. All glassware and stainless materials were heated at $200^{\circ} \mathrm{C}$ for $2 \mathrm{hr}$, cooled, and rinsed with hexane before use.

Surrogate Mixture — Four deuterated isomers of phthalates and one isomer of DEHA were diluted with $n$-hexane, and a portion of each solution was mixed. The concentration of each was $2000 \mathrm{ng} / \mathrm{ml}$.

Sample Extraction and Cleanup — Food samples were extracted by suitable methods depending on their nature as described below. At the start of extraction $1 \mathrm{ml}$ of a surrogates mixture solution was added to the sample. The sampling weights for each food species are listed in Table 3.

Method A: Retort-pouched foods, pizza and gyudon. A homogenized sample was mixed with $100 \mathrm{ml}$ acetonitrile for $1 \mathrm{~min}$, then centrifugated at $3000 \mathrm{rpm}$ for $5 \mathrm{~min}$. The acetonitrile layer was separated and transferred to a separatory funnel, and residual homogenate was mixed again with $100 \mathrm{ml}$ acetonitrile and centrifuged. This layer was gathered, treated with $7 \mathrm{~g} \mathrm{NaCl}$, and vigorously shaken for $5 \mathrm{~min}$. The aqueous layer was removed. To the organic layer, $40 \mathrm{ml}$ hexane saturated with acetonitrile was added, and the solution was shaken. The acetonitrile layer was evaporated to remove the acetonitrile completely. To the residue $5 \mathrm{ml}$ hexane was added, and the extract was transferred to a test tube. After shaking the capped test tube for $30 \mathrm{sec}$, the upper layer was charged on a conditioned Florisil and Bondesil PSA dual layer column, and the eluent was discarded.
Another $5 \mathrm{ml} n$-hexane was added to the test tube and shaken, the $n$-hexane layer was charged on to the column, and the eluent was discarded. Plasticizers were eluted by $20 \mathrm{ml} 5 \%(\mathrm{v} / \mathrm{v})$ acetone in $n$-hexane. The eluate was evaporated and reconstituted in $2 \mathrm{ml} n$-hexane for gas chromatography/mass spectrometry (GC/MS) analysis.

Method B: Sake and wine. To the sample $15 \mathrm{~g}$ $\mathrm{NaCl}$ and $100 \mathrm{ml} n$-hexane were added, and the mixture was vigorously shaken for $5 \mathrm{~min}$. The organic layer was taken, dried over $\mathrm{Na}_{2} \mathrm{SO}_{4}$, evaporated and cleaned using Florisil and Bondesil PSA dual layer column as in Method A.

Method C: Beer. Degassed sample was charged on an Extrelut $20^{\circledR}$ and let stand for $10 \mathrm{~min}$. One hundred $\mathrm{ml}$ of ethyl acetate was passed through the Extrelut $20^{\circledR}$, and the eluent was evaporated to dryness. The residue was cleaned as in Method A.

Method D: Butter, margarine, fat spread. Sample was melted on a water bath then extracted with $100 \mathrm{ml}$ acetone 2 times. The acetone mixture was passed through a glass filter and evaporated to dryness. To the residue $50 \mathrm{ml}$ of $10 \% \mathrm{NaCl}$ solution was added, and plasticizers were extracted by $50 \mathrm{ml}$ ethyl acetate and $n$-hexane mixture $(1: 2) 2$ times. The organic layer was gathered and dried over $\mathrm{Na}_{2} \mathrm{SO}_{4}$ followed by evaporation. To the residue $10 \mathrm{ml} n$-hexane was added, and the plasticizers were extracted with $20 \mathrm{ml}$ acetonitrile 3 times. The lower layer was gathered, evaporated and cleaned as in Method A.

Method E: Vegetable oil. The operation performed was very similar to that used in the study by Kawamura et al. ${ }^{1)}$ The sample was dissolved in $20 \mathrm{ml}$ 
hexane and extracted with $30 \mathrm{ml}$ acetonitrile 3 times. To the acetonitrile layer $250 \mathrm{ml}$ of $10 \% \mathrm{NaCl}$ solution was added, and the plasticizers were extracted with $100 \mathrm{ml} n$-hexane 2 times. The organic layer was dried over $\mathrm{Na}_{2} \mathrm{SO}_{4}$ then evaporated and cleaned as in Method A.

Method F: Infant formula, chocolate, cookies, cheese, snacks, and dry noodles. Sample was extracted with $100 \mathrm{ml}$ acetonitrile 2 times. The acetonitrile layer was treated with $40 \mathrm{ml}$ hexane to remove fat or oil then evaporated and cleaned as in Method A.

Method G: Fresh milk and ice cream. The AOAC method for pesticides ${ }^{8)}$ was modified for plasticizers. To the sample $40 \mathrm{ml}$ water, $50 \mathrm{ml}$ ethanol, $0.5 \mathrm{~g}$ sodium oxalate and $50 \mathrm{ml}$ ether and $n$-hexane mixture $(1: 1)$ were added, and the mixture was shaken for $5 \mathrm{~min}$. The organic layer was separated, and the aqueous layer was extracted 2 more times with $25 \mathrm{ml}$ of an ether and $n$-hexane mixture. The organic layer was gathered and dried over $20 \mathrm{~g}$ $\mathrm{Na}_{2} \mathrm{SO}_{4}$ then evaporated. The residue was dissolved in $100 \mathrm{ml}$ acetonitrile, and fat or oil was removed by extraction in $20 \mathrm{ml} n$-hexane. The acetonitrile layer was evaporated and cleaned as in Method A. GC/MS Conditions — Plasticizers were determined using GC/MS. No specific injection system was used. GC was equipped with a normal septum. The conditions were as follows: GC-17A and GCMS-QP5050 (Shimadzu, Kyoto, Japan) equipped with a methyl silicone-coated fused-silica capillary column DB-5MS $(0.25 \mathrm{~mm}$ i.d. $\times 30 \mathrm{~m}, 0.25 \mu \mathrm{m}$ film thickness, J\&W Scientific, Folsom, CA, U.S.A.) were used. The oven temperature was maintained at $50^{\circ} \mathrm{C}$ for the first $1 \mathrm{~min}$, then ramped up at $10^{\circ} \mathrm{C} /$ $\min$ to $270^{\circ} \mathrm{C}$ where it was held for $27 \mathrm{~min}$. The injection port and interface were kept at $260^{\circ} \mathrm{C}$. Helium (100 kPa) served as the carrier gas. The injection mode was splitless, the sampling time was $3 \mathrm{~min}$, and the injection volume was $1 \mu \mathrm{l}$. An auto injector AOC-20i (Shimadzu) was used. The MS conditions were the following: ionization mode, electron impact, detection voltage, $1.30 \mathrm{kV}$ in usual cases, and $1.00 \mathrm{kV}$ at higher concentration.

Quantification and Confirmation — The plasticizers were determined by comparing their peak areas with those of standards in GC/MS. A blank version of the test performed on the food samples was conducted every day using $50 \mathrm{ml}$ water. All of the blank values were averaged, and the average value was subtracted from the detected plasticizer values. For the plasticizers detected in blank tests, the limit of detection (LOD) was determined to be three times the standard deviation of the blank values. For the other plasticizers, the mechanical limit of GC/MS was considered to be the LOD. The limit of quantification (LOQ) was set at twice the LOD. DINP was determined by the highest five peaks, DALG was determined by the main two peaks, and DINA was determined by all peaks on the chromatogram.

Quality Assurance — The recovery of plasticizers from various food samples was assessed. One $\mathrm{ml}$ of plasticizer solution (in acetonitrile) was added to a food sample $30 \mathrm{~min}$ before extraction. Fortification levels were 0.005 to $4 \mu \mathrm{g} / \mathrm{g}$.

Quantification of ATBC in the Cap Liner

The gasket of the cap was scratched off using a knife, and $0.1 \mathrm{~g}$ of the gasket was extracted with $100 \mathrm{ml} n$ hexane for $16 \mathrm{hr}$ at $37^{\circ} \mathrm{C}$. ATBC in the extract was quantified by GC/MS.

\section{RESULTS AND DISCUSSION}

\section{Analytical Method}

A total of 10 plasticizers were well determined under the GC/MS conditions described in the experimental section. DINP standard was provided as a mixture of isomers and gave a set of peaks similar to what has been previously reported. ${ }^{9)}$ Chromatograms of DAA, DINA, DBS, ATBC and DALG are shown in Fig. 1. Plasticizers that gave more than one peak were quantified by the sum of the area of the peaks. Stable isomers of DBP, BBP, DEHP and DEHA were available, and they were used as surrogates for the isotope dilution technique. Di-n-nonyl phthalate (DNP- $\left.d_{4}\right)$ was used as a surrogate of DINP because the deuterated isomer of DINP was not available. DAA, DINA, DBS, ATBC and DALG were directly quantified, and no internal standard was used.

Table 3 shows the LOD for each kind of food sample. DBP and DEHP exist so ubiquitously that all blank tests indicated their presence at some level. BBP and DEHA also were sometimes detected. The blank values reflect the contamination levels present in the laboratory, reagents and apparatus. They were averaged and subtracted from the detected values of the plasticizers. The LOD was set as 3 times the standard deviation of the blank test values. For plasticizers not found in the blank tests, the mechanical detection limit in GC/MS was set as the LOD. The 

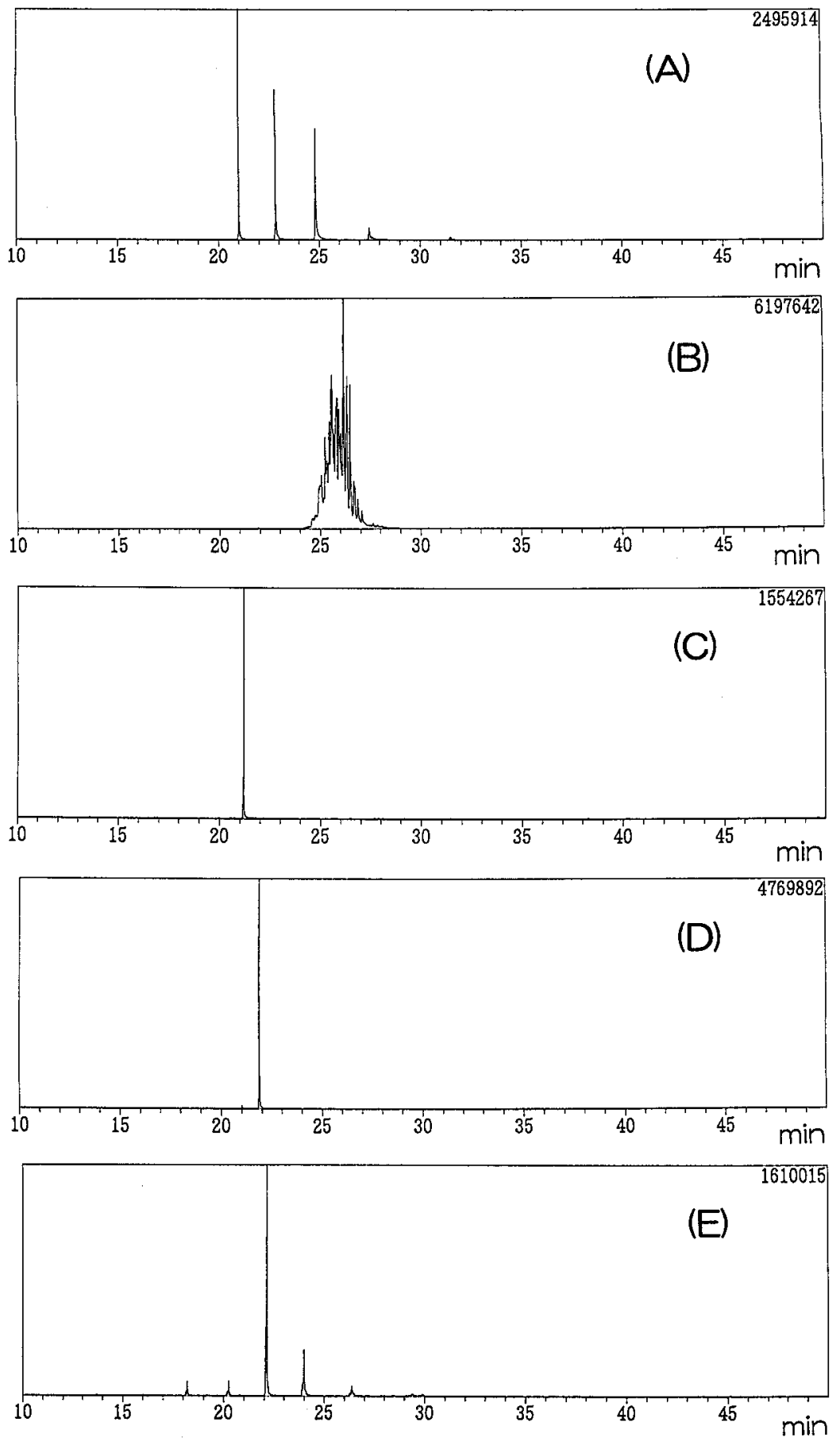

Fig. 1. GC/MS Chromatograms for Plasticizers

(A) DAA; (B) DINA; (C) DBS; (D) ATBC; (E) DALG. GC/MS conditions: instruments: GC-17A and GCMS-QP5050 (Shimadzu); column: DB5MS $\left(0.25 \mathrm{~mm}\right.$ i.d. $\times 30 \mathrm{~m}, 0.25 \mu \mathrm{m}$ film thickness, JandW Scientific; oven temperature: $50^{\circ} \mathrm{C}(1 \mathrm{~min})-\left(10^{\circ} \mathrm{C} / \mathrm{min}\right)-270^{\circ} \mathrm{C}(27 \mathrm{~min})$; injection port and interface temperature: $260^{\circ} \mathrm{C}$; carrier gas: helium (100 kPa); injection mode: splitless; sampling time: 3 min; ionization mode: electron impact; detection voltage: $1.00 \mathrm{kV}$; data acquisition mode: scanning; injection volume: $1 \mu \mathrm{l}$; concentration of each plasticizer: $1 \mathrm{mg} / \mathrm{ml}$.

blank value and LOD depend on the sample weight. They increase as the sample weight decreases. Sampling weight is different for each food species and the method of analysis. Dry or fatty foods were sampled in small amount because they give much interference in GC/MS chromatogram, whereas more aqueous foods were sampled in larger amount. For example, $50 \mathrm{~g}$ of retort-pouched baby foods were sampled, and the LODs for DBP and DEHP were 0.003 and $0.037 \mu \mathrm{g} / \mathrm{g}$ respectively, while $2 \mathrm{~g}$ of but- 
Table 4. Recovery Rates (\%) of Plasticizers from Food Samples $(n=3)$

\begin{tabular}{|c|c|c|c|c|c|c|c|c|c|c|c|c|}
\hline \multirow[b]{2}{*}{ Sample } & \multirow[b]{2}{*}{$\begin{array}{l}\text { Method of } \\
\text { analysis }^{b)}\end{array}$} & \multirow[b]{2}{*}{$\begin{array}{c}\text { sampling } \\
\text { weight }\end{array}$} & \multicolumn{10}{|c|}{ Plasticizer (Added amount: $\mu \mathrm{g}^{a)}$ ) } \\
\hline & & & $\begin{array}{r}\mathrm{DBP}^{c)} \\
(4)\end{array}$ & $\begin{array}{r}\mathrm{BBP}^{c)} \\
(0.5)\end{array}$ & $\begin{array}{r}\mathrm{DEHP}^{c)} \\
(4)\end{array}$ & $\begin{array}{r}\mathrm{DINP}^{c)} \\
(8)\end{array}$ & $\begin{array}{r}\text { DAA } \\
(4)\end{array}$ & $\begin{array}{r}\mathrm{DEHA}^{c)} \\
(0.5)\end{array}$ & $\begin{array}{r}\text { DINA } \\
(4)\end{array}$ & $\begin{array}{r}\text { DBS } \\
(4)\end{array}$ & $\begin{array}{r}\text { ATBC } \\
(4)\end{array}$ & $\begin{array}{r}\text { DALG } \\
(4)\end{array}$ \\
\hline $\begin{array}{l}\text { Retort-pouched } \\
\text { baby food }\end{array}$ & $\mathrm{A}$ & 50 & 96.3 & 98.4 & 101.6 & 124.6 & 70.4 & 82.3 & 32.0 & 77.1 & 106.3 & 75.4 \\
\hline Sake & B & 100 & 99.7 & 98.1 & 98.4 & 103.7 & 87.9 & 99.7 & 89.0 & 86.2 & $\left.\_^{d}\right)$ & 70.3 \\
\hline Wine & B & 100 & 93.4 & 92.3 & 91.8 & 101.1 & 88.7 & 91.4 & 82.2 & 88.4 & 75.9 & 67.4 \\
\hline Beer & $\mathrm{C}$ & 20 & 82.2 & 94.7 & 100.3 & 100.9 & 98.6 & 93.6 & 73.6 & 91.5 & 65.4 & 67.6 \\
\hline Butter & $\mathrm{D}$ & 2 & 96.0 & 94.3 & 92.4 & 117.9 & 88.4 & 92.7 & 62.4 & 89.0 & 99.7 & 90.4 \\
\hline Vegetable oil & $\mathrm{E}$ & 2 & 101.0 & 101.3 & 100.6 & 131.0 & 80.9 & 105.4 & 36.0 & 82.5 & 96.6 & 84.5 \\
\hline Chocolate & $\mathrm{F}$ & 5 & 99.1 & 101.6 & 106.3 & 110.1 & 90.9 & 101.0 & 96.9 & 98.8 & 115.0 & 90.3 \\
\hline Infant formula & $\mathrm{F}$ & 20 & 98.7 & 99.1 & 102.0 & 105.4 & 76.1 & 108.5 & 53.1 & 63.4 & 72.6 & 62.0 \\
\hline Milk & G & 10 & 98.2 & 99.4 & 103.2 & 124.9 & 83.1 & 98.2 & 39.3 & 85.1 & 112.7 & 113.5 \\
\hline Ice cream & $\mathrm{G}$ & 5 & 100.9 & 102.8 & $\_^{d)}$ & 115.4 & 81.2 & 95.9 & 71.6 & 75.2 & 90.9 & 91.3 \\
\hline
\end{tabular}

a) Fortification level depends on the sampling weight. It is calculated by dividing the added amount by the sampling weight. $b$ ) Detail of each method is described in the text. $c$ ) The recovery value was obtained by the isotope dilution technique. $d$ ) Correct recovery data could not be gained because the level of originally contained plasticizer was so high.

ter was sampled and the LODs for the two phthalates were 0.28 and $0.19 \mu \mathrm{g} / \mathrm{g}$ respectively. The LOQ was set at a level of twice the LOD.

A total of 10 kinds of food samples were fortified with plasticizers for the recovery test, and the results are shown in Table 4. The fortification levels were different for each food and plasticizer. Phthalates and DEHA were determined by the isotope dilution technique and were recovered at 82.2-131.0\%. The recovery of DINP in the fortification test was over $100 \%$ as previously reported, ${ }^{2)}$ possibly due to the lower recovery of DNP- $d_{4}(40-70 \%)$ as its surrogate. Deuterated isomer of DINP was not available, so DNP- $d_{4}$ was used instead. The recovery of DINA was lower than $60 \%$ for retort-pouched baby foods, butter, vegetable oil, infant formula and fresh milk. The present method is not suitable for DINA quantification, but played a role in monitoring DINA residue. The recovery rates of ATBC and DALG added to chocolate and fresh milk were more than $110 \%$. This result may be due to an enhanced response in the chromatography due to the 'matrix effect.' ${ }^{10)}$

\section{Plasticizer Levels in Foods and Possible Sources of Contamination}

Table 2 shows the plasticizer levels in 93 samples of retail foods. DBP, BBP, DEHP, DINP, DEHA, ATBC and DALG were detected whereas DAA, DINA and DBS were not detected. Some sources of higher plasticizer contamination in foods have been reported previously, and included not only PVC gloves, but also cling-film, ${ }^{11-14)}$ milk tubing, ${ }^{15)}$ alumi laminate, ${ }^{16)}$ gaskets for glass bottles, ${ }^{16,17)}$ and casings of sausages. ${ }^{18)}$ The possible sources of the plasticizers detected in the present study are discussed below.

DEHP was detected in a retort-pouched baby food sample at a level of $4.25 \mu \mathrm{g} / \mathrm{g}$. This product (Baby Food A) was rice gratin with meat, produced in May 2000. Three samples of Baby Food A produced in September to December 2000 contained less than $0.1 \mu \mathrm{g}$ DEHP/g as shown in Table 5. The authors inquired about the cooking conditions, and the manufacturer reported that DEHP-containing PVC gloves were formerly used in the production of this food, mixing chopped vegetables and butter, but their use was discontinued when the Japanese government prohibited them in June 2000. Thus the high content of DEHP in Baby Food A was presumed to have originated in gloves that came in contact with foodstuffs. This conclusion is supported by the fact that Baby Food A also contained $0.44 \mu \mathrm{g}$ DEHA /g. PVC gloves often contain a low level of DEHA in addition to the main plasticizer DEHP. ${ }^{1,3)}$

In a previous study conducted in 1999, the authors found $5.99 \mu \mathrm{g} \mathrm{DEHP} / \mathrm{g}$ in another retortpouched baby food. The origin of DEHP was sought and found to be a PVC tube used in production. When fatty and hot foodstuffs passed through the tube, high DEHP elution occurred. The manufacturer then changed to a stainless steel tube. Retort-pouched foods are permitted to be produced using PVC tubing. One sample of retort-pouched baby food pro- 
Table 5. Plasticizers in Baby Food A Repeatedly Purchased and Tested ${ }^{a}$

\begin{tabular}{cclccccc}
\hline \hline \multirow{2}{*}{ Sample No. } & \multirow{2}{*}{ Production date } & \multicolumn{5}{c}{ Concentrations $(\mu \mathrm{g} / \mathrm{g})$} \\
\cline { 3 - 7 } & & $\mathrm{DBP}$ & $\mathrm{BBP}$ & DEHP & DINP & DEHA & ATBC \\
\hline 1 & 16 May 2000 & $\mathrm{ND}^{b}$ & 0.003 & 4.25 & $\mathrm{ND}$ & 0.44 & $\left.\mathrm{Tr}^{c}\right)$ \\
2 & 28 Sep 2000 & ND & 0.001 & 0.086 & ND & 0.003 & ND \\
3 & 5 Dec 2000 & ND & 0.002 & 0.099 & ND & 0.004 & ND \\
4 & 26 Dec 2000 & ND & $\operatorname{Tr}$ & $\operatorname{Tr}$ & ND & 0.006 & ND \\
\hline
\end{tabular}

a) DAA, DINA, DBS and DALG were not detected in any sample. $b$ ) ND: not detected. $c$ ) Tr: Trace.

duced by another manufacturer later than June 2000 contained $1.57 \mu \mathrm{g}$ DEHP/g. Such a higher level of DEHP may be due to the use of PVC tubing in production.

In sake bottled in glass cups and sealed with caps, ATBC was found in rather high concentrations, 2.61 to $7.30 \mu \mathrm{g} / \mathrm{g}$. ATBC was detected in the gasket of the cap at levels of $30-48 \%$. It is likely that the ATBC in the sake migrated from the gasket of the cap. ATBC is now expected to replace phthalates as the PVC plasticizer ${ }^{19)}$ but the previous report did not mention the use of ATBC in cap sealing. ${ }^{17)}$ Sake contains $13-19 \%$ ethanol, which could be one reason for the high migration of ATBC. The authors found that DEHP migration occurred from PVC gloves enhanced by ethanol. ${ }^{3)}$

DEHP, DEHA and ATBC were frequently found in dairy products. The fat content of the dairy foods is as follows: butter $>$ cheese $>$ ice cream $>$ milk. $^{20)}$ The levels of plasticizers in these foods have positive relationship with the fat contents. Regardless of the fact that the foods were produced by various companies and that the original milk was taken from a variety of locations in Japan. Fresh milk may be ubiquitously contaminated with the 3 plasticizers, and the contamination levels increase as the fat of the milk is concentrated. The source of the contamination, however, is not clear.

DALG was found in 2 baby food samples, Baby Foods B and C, at levels of 5.47 and $4.76 \mu \mathrm{g} / \mathrm{g}$ respectively (Table 2). These foods were products of the same manufacturer, and both contained tofu hamburg. Each of 2 replicated samples produced on different dates all contained 3.79 to $6.71 \mu \mathrm{g}$ DALG/g. The authors obtained the plastic containers or bags that came in contact with the products and foodstuffs and analyzed them for plasticizers, but no DALG or any of the other plasticizers were detected. Thus the DALG in the product was assumed to have originated in the food additive 'glycerol ester of fatty acids,' which was added to tofu as an anti-bubble agent. The baby food maker speculated that this food additive was used, and the manufacturer of the food additive recognized the identity of this compound and DALG.

The levels of DEHP and DBP in vegetable oils were rather high, to 1.75 and $2.40 \mu \mathrm{g} / \mathrm{g}$ respectively. Fatty foods are often reported to contain plasticizers or the other environmental pollutants.

\section{One-day or One-time Intake of Plasticizers}

Table 6 shows the one-time intake of plasticizers from more highly contaminated foods. The intake is given as a ratio to the body weight of the consumer. The one-time intake of DEHP from one of the retort-pouched baby food samples was found to be $39.5 \mu \mathrm{g} / \mathrm{kg}$ bw, which is very similar to the Japanese TDI of $40 \mu \mathrm{g} / \mathrm{kg}$ bw. This high DEHP may have been due to the use of PVC gloves, and is no longer detected in baby foods as mentioned above. As TDI's are derived on the basis of lifetime exposure, there would be no problem if babies were fed with the baby foods containing DEHP of TDI levels for a certain period.

ATBC intake from the sake was $26.3 \mu \mathrm{g} / \mathrm{kg}$ bw, which is 3800 times smaller than the NOAEL of the $\mathrm{EU}, 100 \mathrm{mg} / \mathrm{kg}$ bw/day. ${ }^{19)}$ DALG intake from the baby food was $62.4 \mu \mathrm{g} / \mathrm{kg}$ bw. It was not a plasticizer but rather a food additive as described above, and it is regarded to be a safe compound for which no guidelines for the level that may be added to foods are specified in Japan.

For the other plasticizers, a total of more than $2 \mu \mathrm{g} / \mathrm{kg}$ bw per one-time intake was not observed in this study. Fat and oil are not generally consumed in high one-time amounts, and so the intake of the contaminants in them are not likely to cause a problem in spite of their higher contamination levels. DBP, BBP, DEHP, DEHA and ATBC that were detected in foods in the present study were not higher than the levels detected in previous research, except for the DEHP detected in Baby Food A. For DINP and 
Table 6. Intake of Plasticizers from the Food Samples — Highest Levels Detected

\begin{tabular}{lcccccc}
\hline \hline Sample & Plasticizer & $\begin{array}{c}\text { Concentration } \\
(\mu \mathrm{g} / \mathrm{g})\end{array}$ & $\begin{array}{c}\text { One-time } \\
\text { food intake } \\
(\mathrm{g})\end{array}$ & $\begin{array}{c}\text { Intake of } \\
\text { plasticizer } \\
(\mu \mathrm{g})\end{array}$ & $\begin{array}{c}\text { Body weight } \\
\text { of consumer } \\
(\mathrm{kg})\end{array}$ & $\begin{array}{c}\text { Intake per } \\
\text { body weight } \\
(\mu \mathrm{g} / \mathrm{kg})\end{array}$ \\
\hline Grape seed oil & DBP & 2.40 & 20 & 48.0 & $\left.50^{a}\right)$ & 0.96 \\
Olive oil & BBP & 0.62 & 20 & 12.4 & $\left.50^{a}\right)$ & 0.25 \\
Retort-pouched baby food A & DEHP & 4.25 & 80 & 340.0 & $8.6^{b)}$ & 39.53 \\
Baby snack & DINP & 1.83 & 3.3 & 6.0 & $\left.7.8^{c}\right)$ & 0.77 \\
Butter & DEHA & 2.78 & 20 & 55.6 & $\left.50^{a}\right)$ & 1.11 \\
Sake & ATBC & 7.30 & 180 & 1314.0 & $\left.50^{a}\right)$ & 26.28 \\
Retort-pouched baby food B & DALG & 6.71 & 80 & 536.8 & $\left.8.6^{b}\right)$ & 62.42 \\
& (food additive) & & & & & \\
\hline
\end{tabular}

a) Body weight of an adult. b) Body weight of 9-month-old baby. $c$ ) Body weight of 6-month-old baby.

DALG, no comparable data exist.

In conclusions, plasticizers in Japanese retail foods were determined by GC/MS. A survey of 93 samples showed a retort-pouched baby food sample to be contaminated by DEHP at the Japanese TDI level. The source of contamination was supposed to be PVC gloves, because the baby food was produced before the prohibition of PVC gloves by the Japanese government. After this prohibition, the baby food product contained a much lower level of DEHP. DEHP and the other plasticizers in the other foods under study were quite low compared to their TDI or NOAEL.

Acknowledgements This study was funded by the Project for Endocrine Disrupting Chemicals of the Ministry of Health and Welfare, which has been reorganized to Ministry of Health, Labor and Welfare.

\section{REFERENCES}

1) Kawamura, Y., Tagai, C., Maehara, T. and Yamada, T. (1999) Additives in polyvinyl chloride and polyvinylidene chloride products. Shokuhin Eiseigaku Zasshi, 40, 274-284.

2) Tsumura, Y., Ishimitsu, S., Saito, I., Sakai, H., Kobayashi, Y. and Tonogai, Y. (2001) Eleven phthalate esters and di(2-ethylhexyl) adipate in oneweek duplicate diet samples obtained from hospitals and their estimated daily intake. Food Addit. Contam., 18, 449-460.

3) Tsumura, Y., Ishimitsu, S., Nakamura, Y., Yoshii, K., Kaihara, A. and Tonogai, Y. (2001) Di(2-ethylhexyl) phthalate contamination of retail packed lunches caused by PVC gloves used in the preparation of foods. Food Addit. Contam., 18, 569-579.

4) Poon, R., Lecavalier, P., Mueller, R., Valli, V. E.,
Procter, B. G. and Chu, I. (1997) Subchronic oral toxicity of di-n-octyl phthalate and di(2-Ethylhexyl) phthalate in the rat. Food Chem. Toxicol., 35, 225239.

5) Lamb, J. C., Chapin, R. E., Teague, J., Lawton, A. D. and Reel, J. R. (1987) Reproductive effects of four phthalic acid esters in the mouse. Toxicol. Appl. Pharmacol., 88, 255-269.

6) Ministry of Health and Welfare, Life and Health Bureau (2000) About the Use of PVC gloves to Foods (14 June 2000), Tokyo.

7) Tsumura, Y., Ishimitsu, S., Nakamura, Y., Yoshii, K., Kaihara, A. and Tonogai, Y. (2001) Contents of eleven phthalates and di(2-ethylhexyl) adipate in retail packed lunches after prohibition of DEHPcontaining PVC gloves for cooking purposes. Shokuhin Eiseigaku Zasshi, 42, 128-132.

8) AOAC International (1999) Pesticide Analytical Manual, Volume I, third Ed., Section 304, Gaithersburg, U.S.A., pp. 11-12.

9) Rastogi, S. C. (1998) Gas chromatographic analysis of phthalate esters in plastic toys. Chromatographia, 47, 724-726.

10) Grob, K. (1993) Split and Splitless Injection in capillary GC, third Ed., Hüthig Buch Verlag GmbH, Heidelberg, Germany, pp. 362-372.

11) Sato, K., Watanabe, Y., Yoshida, R. and Kazama, M. (1986) Analysis of plasticizers in polyvinyl chloride films for food. Annual Report of the Tokyo Metropolitan Laboratory, 37, 228-231.

12) Hirayama, K., Nakaoka, T., Horiguchi, Y. and Watanabe, S. (1991) Migration of adipate plasticizers from polyvinyl chloride films into foods and their decomposition. Jpn. J. Toxicol. Environ. Health, 37, 251-257.

13) Nakamura, Y., Oohata, T., Tsujii, H., Ito, Y., Tatsuno, T. and Tomita, I. (1993) Application of the simultaneous analytical method for plasticizers as food contaminants to the film-packed foods and the 
plasticezer levels in the commercial foods. Nippon Hoso Gakkaishi, 2, 230-238.

14) Harrison, N. (1988) Migration of plasticizers from cling-film. Food Addit. Contam., 5, 493-499.

15) Castle, L., Gilbert, J. and Eklund, T. (1990) Migration of plasticizer from poly(vinyl chloride) milk tubing. Food Addit. Contam., 7, 591-596.

16) Page, B. D. and Lacroix, G. M. (1995) The occurrence of phthalate ester and di-2-ethylhexyl adipate plasticizers in Canadian packaging and food sampled in 1985-1989: a survey. Food Addit. Contam., 12, 129-151.

17) Hirayama, K., Tanaka, H., Kawana, K., Tani, T. and Nakazawa, H. (2001) Analysis of plasticizers in capsealing resins for bottled foods. Food Addit. Contam., 18, 357-362.
18) Van Lierop, J. B. H. and Van Veen, R. M. (1988) Determination of plasticizers in fat by gas chromatography-mass spectrometry. J. Chromatogr., 447, 230-233.

19) CSTEE (1999) Opinion on the toxicological characteristics and risks of certain citrates and adipates used as a substitute for phthalates as plasticisers in certain soft PVC products. Opinion adopted at the 11th CSTEE plenary meeting, EU Scientific Committee for Toxicity, Ecotoxicity and the Environment, Brussels.

20) The Resources Council of the Science and Technology Agency of Japan (2001) Standard Tables of Food Composition in Japan, Fifth Revised Edition, Daiichi-Shuppan Co., Tokyo, Japan. 